\title{
Editorial: Humour in Eastern European countries
}

\author{
Ksenia Shilikhina \\ Voronezh State University \\ shilikhina@rgph.vsu.ru
}

The influence of geographical factors on humour is not frequently discussed in modern humour research. Trying to explain the very nature of humour, researchers are more likely to offer more universal sociological and psychological explanations. So, does geography matter when we talk about humour? To what degree can humour be geographically (i.e., spatially) embedded? The answers to these questions do not seem to be straightforward. On the one hand, many of us know how challenging it can be to explain to people from other countries (and, hence, cultures) what makes a particular joke so funny or to translate humorous texts. Importantly, difficulties in translation can arise not only due to linguistic problems, but also due to the uniqueness of context, specific for a particular area. It means that spatial aspects of humour are intertwined with social, economic and political phenomena. On the other hand, cultures (and, hence, countries) share mechanisms of humour production and understanding, making it possible for cross-cultural transmission of humour.

This special issue of the EJHR is devoted to the studies of humour in Eastern Europe. The contributions written by authors from Belarus, Poland, Bosnia and Herzegovina, Russia and Turkey discuss social and psychological aspects of humour in the Eastern European countries. Long-lasting economic and political challenges create a specific context for eastern Europeans. It comes as no surprise that various humorous genres, e.g., jokes, tweets and demotivational posters, which are discussed in the articles, are geopolitically charged. Thus, in trying to explain the roots of culture-specific humour, each author faces the need to make the geographical, social and political context clear to the reader. However, when it comes to the explanation of the mechanisms of humour, geographical borders open. Therefore, when talking about "Eastern European humour", we will be referring to its specific and universal features, the former arising from unique geopolitical situations in eastern European countries, the latter being the result of common psychological and cognitive mechanisms involved in production and understanding of humour.

What makes Eastern European humour special? The \#ForgivemeFadil Internet campaign discussed in Nihada Delibegović Džanić and Sanja Berberović's paper is a perfect example of an analysis of humour that is performed in a geographically-bound political situation. In order to understand the roots of Bosnian online political humour, the reader needs to get the feeling of what the situation in Bosnia and Herzegovina is like. Contemporary social critique is often expressed through various forms of online humour, especially in the states that are usually referred to as "developing democracies". In their discussion of textual and multimodal (visual and verbal) online memes and humorous demotivators on the Internet, the authors demonstrate how provocative and easily approachable stereotypes are used by Internet users to enhance group cohesion and make a joint political statement to oppose apparently absurd claims of the Bosnian Prime Minister. 
Humorous Twitter messages produced by leaders of various political parties in Turkey are analysed by Gunes Aksan. Again, the geopolitical context in which Twitter humour is performed needs to be explained in detail. In the light of the events that followed the Taksim Gezi Park protests in 2013, the use of Twitter and other social networks as channels for transmitting political claims has become a common practice in Turkish political discourse. The author claims that not only do humorous tweets posted by the leaders of various political parties reflect dominant geopolitical narratives in modern Turkey, but they also allow opposition parties to transform into representatives of the new political force.

Anastasiya Fiadotova examines another important discourse domain-school education. Interestingly, educational discourse is not as state border-dependent as political communication. For this very reason one of the most challenging tasks for the researcher is to delineate the scope of school jokes which can be safely ascribed to the Belarusian culture. Diachronic analysis of the school jokes circulating in Belarus from the 19th century to the present days shows that humour is used as a tool of resistance to ideological pressure of the state. According to Fiadotova, there are a number of reasons that can explain why school has become a target of many jokes in the Belarusian culture. Unlike practical skills, formal education was not highly valued in Belarusian society. This view, along with people's unwillingness to gain theoretical knowledge, made school the object of humour.

Just like in other parts of the world, Eastern Europeans enjoy ethnic humour. Traditionally, in the course of ethnic joke analysis the readers are introduced to historical and cultural contexts in which these jokes exist (see, for instance, Davies 2011). Koncewicz-Dziduch's paper discusses jokes about Montenegrins and demonstrates that jokes about laziness of people from Montenegro serve as signs of a regional stereotype. But, along with historical and sociological data, geography is also involved in the explanation, as the stereotypical perception of Montenegrins and their auto-stereotype largely depend on the geographical position and the climate of the country that allow the people to enjoy slow life.

Alyona Ivanova, Ekaterina Stefanenko and Sergey Enikolopov investigate a variety of humour styles in Russia. The range of factors that can explain why a particular style is employed includes age and gender. Importantly, a series of experimental studies proves that when it comes to the styles of humour, geography also matters. Comparison between styles of humour employed by people living in Moscow and Saint Petersburg and other regions of Russian Federation demonstrates that dwellers of the two capital cities prefer "westernised" humour style, while people living in the regions demonstrate the style that reflects traditional national character.

What makes eastern European humour a part of the "world humour" in general? As I have mentioned earlier, it is the universal mechanisms of humour production and understanding. Researchers offer universal explanations that are free of particular social and political contexts. For instance, Džanić and Berberović use conceptual integration theory (Fauconnier \& Turner 2002) to explain the algorithm of understanding of various genres of the online humour. Another example of a culture- and country-independent explanation why and how humour is created can be found in Aksan's paper. Relying on Bakhtin's notion of carnival (Bakhtin 1984), the author approaches Twitter messages as performative tools in the construction of political interaction.

To sum up, we can say that geographical factors can influence humour production in various ways. State borders as well as natural geographic areas (e.g., capital city life vs. provincial dwelling) create specific social and political contexts, which, in turn, give rise to humour which can be described as geographically-bound. This kind of humour creates a clear sense of place and delineates spatial boundaries within which humour is best performed and understood. Also, geographical location may allow for a specific lifestyle, which, in turn, can 
become the source of ethnic stereotypes and jokes. On the psychological level geographical factor can influence humour styles that people use in their everyday communication.

The papers included in this issue demonstrate "hot topics" in Eastern European countries, since the topics that become targets of the jokes are inherently serious by their nature. A vast amount of humorous discourse is the discourse of protest by nature. Importantly, this humour circulates predominantly online, which makes it possible for ordinary people to have their say. Not surprisingly, protest humour is characteristic not only of political discourse, but it is also a part of educational discourse. Social inequality is an essential property of both discourse domains. For those deprived of power the joy of produces the heeling effect and helps people overcome frustration.

\section{References}

Bakhtin, M. (1984). Rabelais and His World. Bloomington: Indiana University Press. Davies, C. (2011). Jokes and Targets. Bloomington: Indiana University Press. Fauconnier, G. \& Turner, M. (2002). The Way We Think: Conceptual Blending and the Mind's Hidden Complexities. New York: Basic Books. 